\title{
MANEJO E ADAPTAÇÃO DE PASTAGENS DO GÊNERO UROCHLOA EM SOLOS DO CERRADO
}

Larissa Cristhyna de Paula', Andréia Santos Cezário², Nariane Coelho de Oliveira', Milena de Lima Vieira', João Paulo Barros', Eduarda Gonçalves Damascena', Ana Paula Balduíno Rabelo', Wallacy Barbacena Rosa dos Santos ${ }^{2}$

${ }^{1}$ Instituto Federal de Educação, Ciência e Tecnologia Goiano - IFGOIANO, Curso de Zootecnia, Morrinhos, GO. ${ }^{2}$ Instituto Federal de Educação, Ciência e Tecnologia Goiano - IFGOIANO, Dept. de Zootecnia, Morrinhos, GO. E-mail: larissachristynadepaula@gmail.com

\section{RESUMO}

Atualmente, várias espécies do gênero Urochloa vem se destacando, não só no Brasil, como também em outros países, isso deve-se as suas características de bom desempenho e adaptação, consequentemente, alcançando recordes de produção, promovendo ganhos para o produtor. 0 gênero Urochloa tem se destacado como uma alternativa de inclusão no bioma Cerrado, principalmente, no que diz respeito a pecuária brasileira, pois a sua inclusão nesse bioma teve como maior característica, o seu desempenho positivo em solos com baixa fertilidade, o que para outras culturas, devido à sua acidez, apresentavam algumas restrições nutricionais. $O$ gênero Urochloa é destaque quando se trata de bom desempenho na produção de carne e leite, por ser uma gramínea que se adapta muito bem aos diversos climas do país e por ter ótimos valores de produção de massa. Dessa forma, muitos produtores buscam por espécies desse gênero, por serem plantas com uma alta produção de matéria seca, baixos índices de doenças e apresentam crescimento efetivo durante a maior parte do ano, incluindo o período de seca, e também algumas espécies apresentam boa resistência à cigarrinha das pastagens. Levando em consideração a importância econômica e a versatilidade, entre as espécies desse gênero destacam-se a $U$. brizantha, $U$. decumbens, $U$. ruziziensis e $U$, humidicola. Objetivou-se com esta revisão levantar um estudo a respeito do manejo e adaptação de pastagens do gênero Urochloa em solos do bioma Cerrado.

Palavras chave: adubação; degradação; gênero Brachiaria; propagação de sementes.

\section{MANAGEMENT AND ADAPTATION OF UROCHLOA GENDER GRASSES IN CERRADO SOILS}

\begin{abstract}
Currently, several species of the genus Urochloa have been outstanding, not only in Brazil, but also in other countries. This is due to their characteristics of good performance and adaptation, consequently, reaching production records and promoting gains for the producer. The genus Urochloa has been highlighted as an alternative of inclusion in the Cerrado biome, especially with Brazilian livestock, because its inclusion in this biome had as its main characteristic, its positive performance in soils with low fertility, which for other Cultures, because of their acidity, they present some nutritional restrictions. The genus Urochloa stands out when it comes to good performance in the production of meat and milk, because it's a grass that adapts very well to the different climates of the country and it has great values of mass production. In this way, many producers search for species of this genus, because they are plants with a high dry matter production, low disease rates and it presents effective growth during most of the year, including the period of drought, and also some species show good resistance to cigarrinha das pastagens.
\end{abstract}


Taking into account the economic importance and the versatility, among the species of this genus stand out $U$. brizantha, $U$. decumbens, $U$. ruziziensis and $U$. humidicola. The objective of this review was to present a study about the management and adaptation of pastures of the genus Urochloa in soils of Cerrado biome.

Keywords: fertilizer spittlebug; degradation; Brachiaria genus; Propagation of seeds.

\section{INTRODUÇÃO}

No Brasil, a atividade pecuária gera 6,8 milhões de empregos diretos e indiretos, sendo de participação significativa no produto interno bruto (PIB), essa atividade tem destaque econômico no país, principalmente por ter nas pastagens extensivas a principal fonte alimentar do rebanho bovino, isso se deve ao fato de possuírem baixo custo de produção e alto potencial produtivo (ANDRADE et al., 2015a).

Para Silva e Nascimento Júnior (2007), no Brasil, há muito tempo o manejo de pastagens e do pastejo, juntamente com a introdução e avaliação de novos cultivares de gramíneas e leguminosas, têm sido alvos prioritários da experimentação com plantas forrageiras tropicais. Estudos dessa natureza auxiliam em melhorias na produção, pois, estima-se que $80 \%$ das pastagens cultivadas no Brasil Central, responsáveis por mais de $55 \%$ da produção de carne nacional, encontrem-se em degradação, e isso afeta diretamente a sustentabilidade da pecuária (PERON; EVANGELISTA, 2004).

A utilização dessas espécies forrageiras vem sendo utilizada de maneira extrativista, sem a preocupação em repor os nutrientes do solo e manejo adequado, com isso essas gramíneas exaustivamente exploradas entram em um processo de definhamento, com risco marcante na perda de produtividade (COSTA et al., 2006).

A degradação das pastagens e os problemas acarretados por esse processo, explicam a importância de um adequado manejo das pastagens, uma vez que, a degradação das pastagens tem afetado diretamente a sustentabilidade da pecuária nacional, além de diminuir o valor das terras e atrasar a idade de abate dos animais (SILVA; NASCIMENTO JÚNIOR, 2007; CARVALHO, 2005).

Em relação ao Cerrado, sua capacidade de suporte de pastagens foi praticamente triplicada com a introdução do gênero Urochloa, pois, se as pastagens nativas eram utilizadas na base de três a quatro hectares por cabeça e as pastagens de capim gordura ou jaraguá nos cerrados com 0,3 a 0,6 cabeças por hectare, as Urochloas suportam em média 1 a 1,5 cabeça por hectare durante o ano, sendo assim, as espécies deste gênero são consideradas um "divisor de águas" no Brasil Central Pecuário, ou seja, existe a pecuária antes e após a sua utilização (FONSECA, 2010).

As diferentes espécies de braquiária tem recomendações distintas para as condições edafoclimáticas dos cerrados, como por exemplo, a Urochloa humidicola e Urochloa dictyoneura são indicadas para solos úmidos e/ou temporariamente úmidos, com baixa fertilidade ou solos de baixa fertilidade com alto grau de erodibilidade; a Urochloa decumbens pode ser utilizada em solos de baixa a média fertilidade, bem drenados, em regiões de baixa incidência de cigarrinhas; a Urochloa brizantha é recomendada para solos de média a alta fertilidade, bem drenados, em regiões com ou sem cigarrinhas e a Urochloa mutica é indicada para solos úmidos, profundos, de média a alta fertilidade (KICHEL et al., 1999).

Existem várias opções disponíveis para manejar as pastagens e consequentemente melhorar a sua utilização, como por exemplo a adubação das pastagens (DA SILVA; DO AMARAL, 2016); diretamente ou pela rotação com culturas (JAKELAITIS et al., 2014); a introdução de espécies forrageiras superiores (FABRICE et al., 2016); controle da utilização das pastagens através 
da manipulação da taxa de lotação ou do sistema de manejo (DA SILVA NETO et al., 2015); entre outros.

Objetivou-se com esta revisão levantar um estudo a respeito do manejo e adaptação de pastagens do gênero Urochloa em solos do bioma Cerrado.

\section{GÊNERO UROCHLOA (BRACHIARIA)}

Cerca de 100 milhões de hectares no Brasil são de pastagens cultivadas, onde os capins do gênero Urochloa, ocupam mais de $80 \%$ dessa área, sendo o gênero mais cultivado do país, seguido do Cynodon, Panicum, Digitaria, Andropogon entre outros. O antigo gênero Brachiaria teve papel fundamental no Brasil, subsidiando a pecuária de corte no país, principalmente em regiões de solos ácidos e de baixa fertilidade, sendo a base das pastagens cultivadas no país (DA SILVA OLIVEIRA et al., 2016).

A espécie Urochloa brizantha, tem sua origem na África do Sul, e possui um ciclo perene (SILVA, 2015). Alguns pesquisadores indicam que a espécie tem requerimento de precipitação pluviométrica acima de $500 \mathrm{~mm} / \mathrm{ano}$, outros indicam uma exigência de $1.000 \mathrm{~mm}$, é um cultivar que tem forma de crescimento em touceiras semieretas (na maioria dos casos) e que possui um crescimento de 1,0 a 1,20 m, mas, para alguns autores pode chegar a 2,5 $\mathrm{m}$ de altura (DA SILVA JÚNIOR et al., 2016).

À medida que as gramíneas tropicais maturam, há uma redução nos teores de proteína bruta (PB) e elevação nos teores de matéria seca (MS), minerais, e de celulose e lignina, resultando em decréscimo da digestibilidade e aceitabilidade da gramínea (ABREU et al., 2004). Entretanto, o gênero Urochloa apresenta em geral uma digestibilidade e aceitabilidade satisfatórias, com média tolerância à seca, é indicada para solos de média a alta fertilidade. Pode ser utilizada em pastejo e produção de feno, isso se deve a sua boa produção de forragem, que está próxima de 10 a $20 \mathrm{t} \mathrm{ha}^{-1} \mathrm{MS} /$ ano (SILVA, 2014).

Por ser um cultivar que tem pouco enraizamento nos nós, tendo características relevantes, tais como, adaptação a regiões relativamente úmidas, tolerância à seca, consequentemente desenvolvendo-se bem em solos secos, também é tolerante ao frio e, alguns cultivares são resistentes ao ataque de alguns insetos como as cigarrinhas das pastagem, porém, alguns estudos relatam que atualmente, essa resistência tem apresentado sensibilidade, e que, com o avanço do melhoramento genético voltado para essas características, vem desenvolvendo uma maior resistência, também, a outros insetos (SILVA, 2012; PANDOLFI FILHO et al., 2013).

As recomendações para o plantio desse cultivar, indica que o nível de fertilidade do solo deve estar acima da média de fertilidade, tendo uma baixa tolerância em solos mal drenados, é uma planta tolerante a acidez do solo, e sua forma de plantio é através de sementes a lanço, com uma quantidade de sementes necessárias de 7 a $14 \mathrm{~kg} \mathrm{ha}^{-1}$, a profundidade de plantio é de $2 \mathrm{~cm}$ e seu tempo de formação é de 80 a 100 dias, sua utilização pode ocorrer entre os 90 a 120 dias após o plantio (DE PAULA JÚNIOR, 2007).

A temperatura ideal para o desenvolvimento eficaz está entre 30 a $35^{\circ} \mathrm{C}$ e tem uma germinação mínima de $60 \%$. A Urochloa brizantha tem inúmeras vantagens, como a sua boa capacidade de rebrota, é um cultivar ideal para terminação de animais e apresenta boa resposta a adubação, porém, a sua desvantagem é o fato de ser um pouco mais exigente em fertilidade do solo (VILELA, 2005; PIRES, 2006; TSUMANUMA, 2009).

Segundo Fonseca (2010), a espécie Urochloa brizantha está entre as forrageiras de maior utilização, sendo o cultivar mais bem distribuído, podendo ser cultivado em terrenos limpos, com arbustos e as margens de matas.

A espécie Urochloa decumbens é oriunda da importação de sementes da Austrália em meados da década de 1970, mas, é uma espécie de origem africana. Para Fonseca (2010), a U. 
decumbens é a gramínea que tem sido mais utilizada em regiões de clima tropical, desde sua chegada ao Brasil.

A Urochloa decumbens é bastante utilizada por reduzir a infestação de plantas invasoras e também os danos por erosão, devido a sua característica de crescimento intensivo, que cobre o solo rapidamente (DE PAULA JÚNIOR, 2007).

Seu tempo de utilização é estimado entre 90 a 120 após o plantio. Além das características vantajosas citadas a cima, possui também uma boa produção de sementes, é uma planta persistente mesmo quando mal manejada e é caracterizada por sofrer pouco ataque de formigas. Por outro lado tem desvantagens como ser susceptível ao ataque das cigarrinhas-das-pastagens, provocar alta incidência de fotossensibilidade em animais jovens, tem uma alta relação caule/folha quando no seu estado mais maduro e tem uma acirrada competição com as leguminosas (VILELA, 2005; PIRES, 2006).

Espécie Urochloa humidicola, é uma espécie perene que emite vários estolões de espessura fina que se enraízam nos nós. Possui características de boa tolerância ao ataque das cigarrinhas-das-pastagens, grande capacidade de rebrota, boa produção de sementes e adaptação a solos com características ácidas, de baixa fertilidade e sujeitos a alagamentos, tem uma ampla adaptação climática, tem pouca exigência em fertilidade, e é tolerante a solos com altos teores de Al e baixos teores de P. Com tudo, tem formação de pasto lento, porém, uma vez que se é estabelecido, apresenta uma alta capacidade de competição com plantas invasoras, e sua densa cobertura fornece excelentes proteções ao solo contra erosões (DE PAULA JÚNIOR, 2007).

A produção de matéria seca é de 9 a 11 t/ha/ano, com teores de proteína bruta de 5 a $7 \%$ com uma boa aceitabilidade. As condições ideais de plantio quanto a profundidade é de $2 \mathrm{~cm}$, tendo um tempo de formação de 150 a 180 dias. As recomendações de bom desenvolvimento em solos com fertilidade baixa, a época do plantio é nos períodos chuvosos, a forma de plantio é através de sementes a lanço, utilizando a quantidade de sementes de 8 a $14 \mathrm{~kg} / \mathrm{ha}$, sua temperatura ideal de desenvolvimento está em torno de 32 a $35^{\circ} \mathrm{C}$ e possui uma germinação de 25\% (VILELA, 2005).

O gênero Urochloa inclui aproximadamente cerca de 100 espécies, principalmente as de origem tropical e subtropical africana. A introdução da braquiária, praticamente triplicou a capacidade de suporte das pastagens nos cerrados, pois as braquiárias suportam de 1 a 1,5 de cabeças em média por hectare durante o ano, em comparação com as pastagens nativas como, capim gordura ou Jaraguá, suportando 0,3 a 0,6 cabeças por hectare (FONSECA, 2010).

Quanto ao clima e ao solo, se adaptam bem às condições de clima e solo do Brasil Central, com isso, pesquisadores relatam que as braquiárias vão bem em solos com baixa fertilidade, entretanto, em solos com correção de acidez e adubação do solo adequadas, as respostas são ainda mais satisfatórias. Quanto ao valor nutritivo, no período das águas, costuma-se ocorrer uma elevação nos teores de proteína, caindo muito nos períodos secos ao ano. No entanto, na maior parte dos casos, os animais conseguem se manter sem necessidade de complementação de alimentos (SILVA, 2014).

\section{CATEGORIA ANIMAL}

O estabelecimento das bases de manejo na utilização de pastagens, devem ter enfoque não somente em conhecimentos isolados sobre as plantas forrageiras a serem utilizadas, aos solos e a nutrição dos animais, mas também, a fatores como o entendimento da relação planta-animal, onde, para obter esse entendimento, é necessário um direcionamento no sentido de estudar os processos e as opções do animal na busca pelo alimento na pastagem, levando em consideração as características quantitativas, qualitativas e estruturais da pastagem (TEIXEIRA et al., 2011).

Para Andrade et al. (2015b) a produção animal baseada em forragens é o fator de destaque que torna o Brasil forte neste setor, porém, devem ser feitas melhorias nas práticas de manejo e 
alimentação. Entre os problemas existentes na criação de bovinos a pasto, está presente a variação tanto na quantidade como também na qualidade da matéria seca que é produzida, o que pode afetar negativamente a produtividade animal (SILVA et al., 2010). Todavia, tem-se observado a adoção da prática da suplementação a pasto pelos pecuaristas na terminação dos bovinos, principalmente na época da seca, atitude que vem demonstrando bons resultados (ANDRADE et al., 2015b).

Arrisca-se dizer que dentre as pastagens mais utilizadas entre os produtores de pequeno e médio porte, está o gênero Urochloa. Sendo também utilizada como base alimentar de ovinos, porém, com rigoroso cuidado com o manejo, para que não ocorra a possibilidade de causar nos animais a fotossensibilização, que tem como sintoma principal a irritação na pele, mas que em casos mais graves pode levar o animal a morte (MOREIRA; YOSHIHARA, 2013).

Os valores proteicos de um alimento são fatores limitantes ao desenvolvimento dos animais, as forragens de clima tropical, possuem pouca informação no que diz respeito ao teor de proteína. Alguns produtores optam por utilizar a suplementação com altas quantidades de proteínas, podendo obter-se um ganho de peso adicional de aproximadamente 200 a $300 \mathrm{~g} / \mathrm{dia}$ (FERNANDES et al., 2010).

Em estudos conduzidos por Mauro e Parente (2006), foi avaliado o comportamento de bezerros em pastejo diferenciados de Urochloa decumbens e Urochloa brizantha manejadas em uma mesma altura, e observou-se que houve diferenças no desempenho dos animais, assim, concluiu-se que o ideal seria a utilização de estratégias de manejo do pastejo, levando em consideração as diferenças em relação ao comportamento dos animais em pastejo, considerando também que o tempo que é gasto nas atividades de pastejo determinarão a quantidade de forragem ingerida, os gastos de energia com a captura da forragem e consequentemente $o$ desempenho dos animais em pastejo.

\section{NUTRIÇÃO DO SOLO}

De acordo com Costa et al. (2006), as gramíneas do gênero Urochloa, são as espécies forrageiras mais conhecidas no país, e foram introduzidas no cerrado como meio de se cultivar os solos de baixa fertilidade que, devido à sua acidez, apresentavam sérias restrições nutricionais às culturas. Para Silva e Resck (1997), os solos de cerrado caracterizam-se por serem altamente intemperizados e com baixa fertilidade natural.

Segundo Costa et al., (2006), a fração argilosa dos solos do cerrado é, basicamente, constituída por minerais de argila 1:1 e óxidos de Ferro (Fe) e Alumínio (Al), o que determina uma baixa densidade de carga superficial líquida negativa e, em consequência, baixa capacidade de troca catiônica (CTC), quando comparada aos minerais 2:1 e a própria MO. Em estudos conduzidos por Arruda (1982), foi constatado que as gramíneas do gênero Urochloa toleram suficientemente a toxidez do solo por alumínio, e que os teores crescentes de alumínio não afetam o rendimento da Urochloa decumbens.

Para Costa et al. (2006) é de suma importância, manter os níveis ideais de fertilidade do solo, para obter resultados satisfatórios na produção de carne e leite, porém, para que isso ocorra, é necessário estabelecer um manejo adequado, mantendo a fertilidade do solo em níveis favoráveis ao desenvolvimento da planta, incluindo as adubações nitrogenadas complementares, pois o nitrogênio é um dos nutrientes que mais limitam a produtividade, e se houver deficiência desse nutriente no solo o crescimento será afetado, as plantas ficarão com um porte pequeno e com poucos perfilhos e o teor se torna insuficiente para atender as exigências de determinada planta (KLUTHCOUSKI; AIDAR, 2003).

Diante da deficiência em nutrientes do solo brasileiro, o fósforo tem sua importância ressaltada ao estabelecimento da pastagem, bem como no armazenamento, transporte e utilização de energia no processo de fotossíntese, influenciando também o crescimento das raízes 
e no perfilhamento das plantas (CORREA; HAAG, 1993; MACIEL et al., 2007; RODRIGUES FILHO et al., 2014).

Martinez e Haag (1980) ao pesquisarem sete espécies de gramíneas, concluiu que as mais eficientes na absorção e na utilização de fósforo foram as espécies de Urochloa ressaltando que a $U$. decumbens foi a que obteve maior eficiência na absorção e na utilização do fósforo. As Urochloas são consideradas plantas com capacidade de vegetar em solos com baixas concentrações de fosforo não requerendo mais que $45 \mathrm{Kg} \mathrm{ha}^{-1}$ de $\mathrm{P}_{2} \mathrm{O}_{5}$. Para que a adubação fosfatada tenha eficiência e outra fonte qualquer de fósforo, deve ser levado em consideração o tipo de solo, a espécie da planta forrageira e as características do tipo de fósforo utilizado (CAMACHO et al., 2015; NUNES, 2016).

Outro mineral de extrema importância é o potássio, responsável pelo metabolismo vegetal atuando na transformação de energia luminosa para energia química e também responsável pela translocação dos carboidratos sintetizados no processo fotossintético (TAIZ; ZEIGER, 2004). Os capins deficientes em potássio apresentam colmos finos, raquíticos e pouco resistentes ao tombamento e as folhas são pouco desenvolvidas apresentando coloração normal (MALAVOLTA, 1980).

Diante da importância dos macro nutrientes citados acima, é notada uma certa preocupação atualmente, no que se diz respeito aos cuidados com os solos e vegetação do Cerrado.

\section{ALTURA DE CORTE}

O sucesso na utilização das pastagens depende não apenas da escolha da planta forrageira, mas também da compreensão dos mecanismos morfofisiológicos e de sua interação com o ambiente (NASCIMENTO JÚNIOR et al., 2002). De acordo com Silva et al. (2015) a desfolhação por meio do monitoramento e controle da altura do dossel é uma estratégia que pode trazer informações relevantes sobre o comportamento da planta forrageira.

A solução para este problema está vinculada a utilização consciente da pastagem, dando assim a chance da mesma de se recuperar dos processos de exploração. Para que haja esse uso consciente é de fundamental importância conhecer o funcionamento fisiológico da planta, pois o sucesso na utilização das pastagens não depende apenas da disponibilidade de nutrientes ou da escolha da espécie forrageira, mas também da compreensão dos mecanismos morfofisiológicos e de sua interação com o ambiente e do manejo (DA SILVA, 2010).

No Brasil as pastagens correspondem a um dos maiores ecossistemas, são grupos complexos que são influenciados por fatores bióticos e abióticos, o que relativamente determina as amplitudes de respostas tanto de animais, quanto de plantas. A desfolha realizada por meio de monitoramento e controle de altura do dossel, é uma boa alternativa para obter informações sobre o comportamento das plantas forrageiras (CARVALHO et. al. 2009; SILVA et. al., 2010).

Para um manejo adequado de pastagens, busca-se uma base de equilíbrio entre a produção e qualidade da forrageira, com o intuito de obter os requerimentos nutricionais dos animais, afim de garantir, simultaneamente, a persistência da produtividade da pastagem. Com isso, o controle relacionado a frequência, intensidade de desfolha e altura de resíduo constituem em um mecanismo fundamental para uma maior eficácia na produção e utilização do dossel (OLIVEIRA et. al., 2007; DE LUCENA et. al., 2016).

A baixa disponibilidade e qualidade da forragem, pode ser consequência da utilização de pastejo contínuo ou em períodos mínimos de descanso. Altas intensidades de desfolha, também são fatores que contribuem para uma baixa disponibilidade e qualidade da forragem, consequentemente, com reflexos negativos quando relacionados aos índices de desempenho zootécnico dos animais. A Urochloa ruziziensis se destaca como uma das espécies forrageiras mais utilizadas por agricultores de grãos (FERREIRA et al. 2015). Porém, as informações sobre o manejo 
desta forrageira é escasso, quanto à intensidade de pastejo e os impactos sobre as cultivares de soja em sucessão (FRANCHINI et al. 2015; DE LUCENA et. al. 2016).

A maioria dos pastos de Urochloa decumbens são manejados sob lotação contínua, devido a maior facilidade operacional desse tipo de pastejo quando comparado a modalidades como o método de pastejo intermitente. A variação no manejo do pastejo, junto a redução da altura média do pasto nas estações de inverno, pode apresentar resultados na primavera subsequente, em situações em que o pasto está com estrutura favorável ao pastejo, que se caracteriza com maior espessura de lâminas foliares no dossel (SANTOS et. al., 2010; SANTOS et. al. 2011).

Lupinacci (2002), realizou uma experimentação buscando avaliar a produção de forragem da Urochloa brizantha em diferentes tamanhos de entrada do rebanho nos piquetes, submetida a intensidades de pastejo por bovinos de corte. Os tratamentos correspondem a quatro alturas de pasto $(10,20,30$ e $40 \mathrm{~cm})$, mantidas em steady state, e foram alocadas as unidades experimentais conforme um delineamento de blocos completos casualizados, com quatro repetições. A altura do pasto de $10 \mathrm{~cm}$ correspondeu a uma condição de desfolha drástica, de modo que o manejo do pastejo deveria ser efetuado entre as condições de pasto de 20 e $40 \mathrm{~cm}$. A escolha da condição de pasto mais indicada deve ser feita mediante o objetivo da atividade e a natureza de exploração animal proposta.

Alguns estudos sobre o manejo de plantas forrageiras, utilizando pastagens com gramíneas de clima tropical, tem indicado a existência de uma condição ideal, para que ocorra a interrupção do período de rebrotação de pastos, que geralmente estão relacionados ao momento em que o dossel intercepta aproximadamente $95 \%$ de radiação fotossintetizante (CARNEVALLI et al., 2006; BARBOSA et al., 2007).

\section{PROPAGAÇÃO}

Segundo Souza et al. (2017), o Brasil se destaca no cenário mundial por sua produção de espécies forrageiras, apresentando um desenvolvimento significativo nos últimos anos. Para Abrasem (2014) a produção de sementes de espécies forrageiras aumentou de 27 milhões de toneladas em 2010, para 50 milhões de toneladas em 2013.

A multiplicação do gênero Urochloa se dá por sementes, dando-se preferência as mudas, uma vez que a produção de sementes costuma ser relativamente baixa, sendo considerada impraticável (NUNES et al., 1984).

Segundo Rocha (1986) o gênero Urochloa chama atenção pela notável capacidade de domínio ecológico em solos ácidos e de baixa fertilidade, sendo que as espécies $U$. decumbens e, recentemente, $U$. brizantha vêm trazendo solução provisória para a produção animal nos cerrados. Segundo Marcos Filho et al., (1987), o período de germinação dessas espécies varia, geralmente, de 15 a 18 dias.

Estudos realizados com sementes do gênero Urochloa demonstraram que os envoltórios (gluma, pálea e lema) constituem uma barreira para a germinação. Pois o principal fator que se dá essa barreira é a presença de dormência. Na Tabela 1 estão apresentadas quantidades aproximadas do número de sementes para algumas espécies de Urochloa. 
Tabela 1. Número aproximado de sementes por grama de várias espécies de forrageiras e sugestão de semeadura a serem feitas no início do período chuvoso.

\begin{tabular}{lcc}
\hline Éspécies forrageiras & $\begin{array}{c}\text { Número aproximado de } \\
\text { sementes/grama }\end{array}$ & $\begin{array}{c}\text { Taxa de semeadura (kg } \\
\text { ha }^{-1} \text { *SPV) }\end{array}$ \\
\hline Brachiaria brizantha & 150 & 2,80 \\
\hline Brachiaria decumbens & 200 & 1,80 \\
\hline Brachiaria humidicola & 207 & 2,50 \\
\hline Brachiaria ruziziensis & 230 & 2,00
\end{tabular}

Fonte: Souza (1993).

*SPV - Sementes puras viáveis

Para Peron e Evangelista (2004) é de suma importância conhecer a qualidade das sementes disponíveis no mercado, bem como a quantidade a ser utilizada no plantio, utilizar sementes sem conhecimento do seu valor cultural pode conduzir ao risco de semear uma quantidade abaixo do ideal, podendo, na maioria das vezes, conduzir a uma baixa densidade de plantas por área, o que possibilita a competição por ervas daninhas, além de que, o tamanho das sementes é outro fator importante, pois é possível que ocorra variações entre espécies, e até mesmo dentro de uma mesma espécie, porque sementes maiores, por acumular mais reservas, tendem a se sobressair mais, em detrimento de sementes menores, em condições adversas, ou seja, maiores profundidades.

\section{CONSIDERAÇÕES FINAIS}

$\mathrm{Na}$ literatura existem trabalhos, pesquisas e livros atualizados com informações sobre as exigências das plantas forrageiras quanto a adubação e fertilidade do solo. Não somente isso, como também, pesquisas sobre o manejo adequado da pastagem para com o animal, o que é extremamente importante no sistema de produção. Esses trabalhos, podem e devem ser utilizados em propriedades pecuárias, como guias de correção e manejo tanto do solo, para obterse uma boa produção de massa verde com o cultivar a ser utilizado, quanto com o manejo dos animais, para que se possa ter uma melhor produção.

\section{REFERÊNCIAS}

ABRASEM (ASSOCIAÇÃO BRASILEIRA DE SEMENTES). Sementes é tecnologia. Revista Agroanalysis, v.4, n.2, p.31-37, 2014. Disponível em: http://www.abrasem.com.br/wpcontent/uploads/2014/04/Mat\%C3\%A9ria-Semente-\%C3\%A9-Tecnologia.pdf

Acessado:

12/04/2017.

ABREU, J.B.R.; CÓSER, A.C.; DEMINICIS, B.B.; BRUM, R.P.; SANT'ANA, N.D.F.; TEIXEIRA, M.C.; SANTOS, A.M. Avaliação da produção de matéria seca, relação folha/colmo e composição químicobromatológica de Brachiaria humidicola (rendle), submetida à diferentes idades de rebrota e doses de nitrogênio e potássio. Revista Universidade Rural: Série Ciência da Vida, v. 24, n. 1, p. 135-141, 2004.

ANDRADE, A.T.; ROSSI, R.C.; STIVAL, V.P.; DE OLIVEIRA, E.A.; SAMPAIO, A.A.M.; ROSA, B. L. Diferentes suplementos na terminação de bovinos Nelore em pastagem diferida de Brachiaria 
decumbens no período da seca. Boletim de Indústria Animal, v. 72, n. 2, p. 91-101, 2015 b. https://doi.org/10.17523/bia.v72n2p91

ANDRADE, R.G.; CASTRO TEIXEIRA, A.H.; LEIVAS, J.F.; DA SILVA, G.B.S.; NOGUEIRA, S.F.; CASTRO VICTORIA, D.; VICENTE, L.E.; BOLFE, É. L. Indicativo de pastagens plantadas em processo de degradação no bioma Cerrado. In: Proc. Brazilian Symposium on Remote Sensing. 2015a. p. 15851592.

ARRUDA, M.L. Introdução de alumínio em gramíneas forrageiras: tolerância e efeitos de formas de nitrogênio. 1982, 141p. Tese (Mestrado) - Universidade Federal do Rio de Janeiro, Rio de Janeiro.

BARBOSA, R.A.; NASCIMENTO JÚNIOR, D. do; EUCLIDES, V.P.B.; SILVA, S.C. da; ZIMMER, A.H.; TORRES JÚNIOR, R.A. de A. Capim-tanzânia submetido a combinações entre intensidade e frequência de pastejo. Pesquisa Agropecuária Brasileira, v.42, p.329-340, 2007.

CAMACHO, M.A.; SILVEIRA, L.P.O.; SILVEIRA, M.V. Efficiency of genotypes of Brachiaria brizanthaStapf.(Syn: Urochloa brizantha) in biomass production under phosphorus application. Arquivo Brasileiro de Medicina Veterinária e Zootecnia, v. 67, n. 4, p. 1133-1140, 2015. https://doi.org/10.1590/1678-4162-6763

CARNEVALLI, R.A.; SILVA, S.C. da; BUENO, A.A.O.; UEBELE, M.C.; HODGSON, J.; SILVA, G.N.; MORAIS, J.P.G. Herbage production and grazing losses in Panicum maximum cv. Mombaça under four grazing managements. Tropical Grasslands, v.40, p.165-176, 2006.

CARVAlHO, P. C. D. F.; TRINDADE, J. K. D.; MEZZALIRA, J. C.; POLI, C. H. E. C.; NABINGER, C.; GENRO, T. C. M.; GONDA, H. L. Do bocado ao pastoreio de precisão: compreendendo a interface planta-animal para explorar a multi-funcionalidade das pastagens. Revista brasileira de zootecnia = Brazilian journal of animal science. Viçosa, MG. Vol. 38, supl. especial (2009), p. 109-122, 2009.

CARVALHO, P.C.F. O manejo da pastagem como gerador de ambientes pastoris adequados à produção animal. In: MOURA, J.C.; DA SILVA, S. C; DE FARIA, V.P. (Eds.) SIMPÓSIO SOBRE MANEJO DA PASTAGEM, 22., 2005, Anais... Piracicaba: FEALQ, 2005. p.07-31.

CORREA, L.A.; HAAG, H.P. Níveis críticos de fósforo para o estabelecimento de gramíneas forrageiras em Latossolo Vermelho Amarelo, álico: II. Experimento de campo. Scientia Agricola, v. 50, n. 1, p. 109-116, 1993. https://doi.org/10.1590/S0103-90161993000100015

COSTA, K.A.P.; DE OLIVEIRA, I.P.; FAQUIN, V. Adubação nitrogenada para pastagens do gênero Brachiaria em solos do Cerrado. Embrapa Arroz e Feijão. Documentos, 2006.

DA SILVA, J.C.M.; DO AMARAL, P.N. C. ACOMPANHAMENTO DAS ATIVIDADES PRODUTIVAS NAS PROPRIEDADES RURAIS DO MUNICÍPIO DE ANASTÁCIO-MS. ANAIS DO SEMEX, n. 8, 2016.

DA SILVA JÚNIOR, U.P.; SCOPEL, I.; DA ASSUNÇÃO, H.F. PARTIÇÕES PLUVIOMÉTRICAS NO CULTIVO DE BRAQUIÁRIA, NO MUNICÍPIO DE JATAÍ (GO). Revista de Geografia-PPGEO-UFJF, v. 5, n. 2, 2016. 
DA SILVA NETO, S.P.; DOS SANTOS, A.C.; GARCIA, R.N.; DIAS, J.L.A.; SILVA, Á. M.; PEREIRA, P.A.R. Variabilidade espacial da biomassa da forragem e taxa de lotação animal em pastagem de capim Marandu. Revista Agrogeoambiental, v. 8, n. 2, 2015.

DA SILVA OLIVEIRA, V.; DA SILVA MORAIS, J. A.; FAGUNDES, J.L.; LIMA, I.G.S.; SANTANA, J.C.S.; DOS SANTOS, C.B. Efeito da irrigação na produção e qualidade de pastagens durante o período da seca. Revista Científica Eletrônica de Medicina Veterinária, v. 26, n. 1, p. 1-10, 2016.

DE LUCENA, N. C.; TOWNSEND, C. R., DOS SANTOS, F. H. F.; MAGALHÃES, J. A., DE SEIXAS, F. J. S.; RODRIGUES, B. H. N. Rendimento de forragem e morfogênese de Brachiaria brizantha cv. Marandu sob diferentes períodos de descanso. PUBVET, v. 10, p. 271-355, 2016.

DE PAULA JÚNIOR, T. J. 101 culturas: Manual de tecnologias agrícolas. EPAMIG, 2007.

FABRICE, C.E.S.; SOARES FILHO, C.V.; PINTO, M.F.; PERRI, S.H.V.; CECATO, U.; MATEUS, G.P. Recuperação de pastagens de" Brachiaria decumbens" degradada com introdução de Stylosanthes e adubação fosfatada. Revista Brasileira de Saúde e Produção Animal, v. 16, n. 4, p. 758-771, 2016. https://doi.org/10.1590/S1519-99402015000400001

FERREIRA, G. A., OLIVEIRA, P. S. R. D.; ALVES, S. J.; COSTA, A. C. T. D. 2015. Soybean productivity under different grazing heights of Brachiaria ruziziensis in an integrated crop-livestock system. Revista Ciência Agronômica 46: 755-763. https://doi.org/10.5935/1806-6690.20150063

FONSECA, D. M. F. Plantas forrageiras. Ed. UFV, 2010.

FERNANDES, L.O.; REIS, R. A.; PAES, J. M. V. Efeito da suplementação no desempenho de bovinos de corte em pastagem de Brachiaria brizantha cv. Marandu. Ciência e Agrotecnologia, p. 240-248, 2010. https://doi.org/10.1590/S1413-70542010000100031

FRANCHINI, J. C.; JUNIOR, A. A. B.; DEBIASI, H.; CONTE, O. Crescimento da soja influenciado pela adubação nitrogenada na cultura, pressão de pastejo e épocas de dessecação de Urochloa ruziziensis. Revista Agro@ mbiente On-line, v. 9, n. 2, p. 129-135, 2015.

JAKELAITIS, A.; CARDOSO, I.S.; SOARES, M.P. BANCO DE SEMENTES DE PLANTAS DANINHAS EM SOLOS CULTIVADOS COM CULTURAS E PASTAGENS-10.14688/1984-3801/gst. v7n2p63-73. GLOBAL SCIENCE AND TECHNOLOGY, v. 7, n. 2, 2014.

KICHEL, A. N.; MIRANDA, C. H. B.; ZIMMER, A. H. Degradação de pastagens e produção de bovinos de corte com a integração agricultura x pecuária. In: Simpósio de Produção de Gado de Corte, v. 1, p. 201-234, 1999.

KLUTHCOUSKI, J.; AIDAR, H. Uso da integração lavoura-pecuária na recuperação de pastagens. In: KLUTHCOUSKI, J.; STONE, L. F.; AIDAR, H. (Ed.). Integração lavoura-pecuária. Santo Antônio de Goiás: Embrapa Arroz e Feijão, 2003. p. 185-223.

LUPINACCI, A.V. Reservas orgânicas, índice de área foliar e produção de forragem em Brachiaria brizantha cv. Marandu submetida a intensidades de pastejo por bovinos de corte. 2002. Tese de Doutorado. Universidade de São Paulo. https://doi.org/10.11606/D.11.2002.tde-27082002135702 
MACIEL, G.A.; DE ANDRADE, S.E.G.V.; FERREIRA, M.M.; EVANGELISTA, A.R. Efeito de diferentes fontes de fósforo na Brachiaria brizantha cv. Marandu cultivada em dois tipos de solos. Ciência Animal Brasileira, v. 8, n. 2, p. 227-234, 2007.

MALAVOLTA, E. Elementos de nutrição mineral de plantas. São Paulo: Agronômica Ceres, 1980. 228p.

MARTINEZ, H.E.P; HAAG, H.P. Níveis críticos de fósforo em Brachiaria decubens. Anais da Escola Superior de Agricultura "Luiz Queiroz", Piracicaba, v.32, p.912-977, 1980.

MAURO, A. M. Z. E.; PARENTE, S.H.N. Comportamento ingestivo de bezerros em pastos de Brachiaria brizantha e Brachiaria decumbens. Ciência Rural, v. 36, n. 5, 2006.

MARCOS FILHO; CÍCERO, S.M.; SILVA, W.R. Avaliação da qualidade das sementes. Piracicaba: FEALQ, 1987. 230p.

MOREIRA, A.L.; YOSHIHARA, E. Capim Bachiaria na criação de ovinos. Pesquisa \& Tecnologia, vol. 10, n. 2, Jul-Dez 2013.

NASCIMENTO JÚNIOR, D.; GARCEZ NETO, A.F.; BARBOSA, R.A.; ANDRADE, C.M.S. Fundamentos para o manejo de pastagens: Evolução e atualidade. In: OBEID et al. (Eds.). SIMPÓSIO SOBRE MANEJO ESTRATÉGICO DA PASTAGEM, 2002, Viçosa. Anais... Viçosa, MG: UFV, 2002. p. 149-196. NUNES, M.T. Estabelecimento de Brachiaria humidicola cv. comum sob adubação fosfatada em solo do Estado Amazonas. 2016. 65p. Dissertação (Mestrado em Agronomia Tropical) Universidade Federal do Amazonas. Manaus - AM, 2016.

NUNES, S.G.; BOOK, A.; PENTEADO, M.I.O.; GOMES, D.T. Brachiaria brlzantha cv. Marandu. Campo Grande: Embrapa-CNPGC, 1984, 31p.

OLIVEIRA, A. B.; PIRES, A. J. V.; MATOS NETO, U. M.; CARVALHO, G. G. P.; VELOSO, C. M.; SILVA, F. F. Morfogênese do capim-tanzânia submetido a adubações e intensidades de corte. Revista Brasileira de Zootecnia, Viçosa, MG, v. 36, n. 4, p. 1006-1013, 2007.

PANDOLFI FILHO, A.D.; DO VALLE, C.B.; VIEIRA, H.D.; DEMINCIS, B.B.; ROSÁRIO, P.; ARAÚJO, P. Capítulo 5-0 gênero Brachiaria e seu melhoramento genético. Bruno Borges Deminicis Carla Braga Martins, p. 43, 2013.

PERON, A.J.; EVANGELISTA, A.R. Degradação de pastagens em regiões de cerrado. Ciência e Agrotecnologia, v. 28, n. 3, p. 655-661, 2004. https://doi.org/10.1590/S1413-70542004000300023

PIRES, W. Manual de pastagem: formação, manejo e recuperação. Aprenda Fácil Editora, 2006. ROCHA, G. L. Perspectivas e problemas de adubação de pastagens no Brasil. In Simpósio sobre Calagem e Adubação de Pastagens, 1. Nova Odessa. Anais. Potafos, Piracicaba, SP. p. 1-30. 1986.

RODRIGUES FILHO, J.L.; DOS SANTOS, M.C.; LIMA, B.L.; MARTINS, L. B.; FREITAS PAIVA, F. PRODUÇÃO DE MASSA SECA EM BRACHIARIA DECUMBENS CV. BASILISK CULTIVADO EM VASOS SOB DIFERENTES NÍVEIS DE FÓSFORO. Anais do Encontro de Pesquisa e Extensão do Câmpus São Luís de Montes Belos, v. 1, n. 2, 2014. 
SANTOS, M.E.R.; FONSECA, D. M.; GOMES, V. M.; SILVA, S.; ALBINO, R. L. Características estruturais do capim-braquiária sob regimes de lotação continua com bovinos. Enciclopédia Biosfera, v.6, n.10, p.1-10, 2010.

SANTOS, M. E. R.; FONSECA, D. M.; GOMES, V. M.; GOMIDE, C. A. M.; NASCIMENTO JR, D., QUEIROZ, D. S. Capim-braquiária sob lotação contínua e com altura única ou variável durante as estações do ano: morfogênese e dinâmica de tecidos. Revista Brasileira de Zootecnia, v. 40, n. 11, p. 2323-2331, 2011. https://doi.org/10.1590/S1516-35982011001100007

SILVA, D.M. Seleção de genótipos em Brachiaria ruziziensis para resistência a Collaria oleosa (Distant, 1863) (Hemiptera: Miridae). 2012. Tese de Doutorado. Universidade Federal de Lavras. 2012.

SILVA, J.C.; SILVA, A.P.; GOMES, M.B.; MENDONÇA, P.R.F.; LEAL, N.B.C.; PANTALEÃO, T.F.; ALMEIDA, J.S.M.; BAILÃO, L.L.; SILVA TRINDADE, J. CARACTERÍSTICAS MORFOGÊNICAS E ESTRUTURAIS DA BRACHIARIA HÍBRIDO CV. MULATO II SUBMETIDO A DIFERENTES ALTURAS DE CORTE. Revista Eletrônica Interdisciplinar, v. 2, n. 14, 2015.

SILVA, J. E.; RESCK, D. V. S. Matéria orgânica do solo. In: VARGAS, M. A.T.; HUNGRIA, M. (Ed.). Biologia dos solos dos cerrados. Planaltina, DF: EMBRAPA-CPAC, 1997. p. 467-516.

SILVA, L.L.G.G.; ALVES, G.C.; RIBEIRO, J.R.A.; URQUIAGA, S.; SOUTO, S.M; FIGUEIREDO, M.V.B.; e BURITY, H.A. Fixação biológica de nitrogênio em pastagens com diferentes intensidades de corte. Arquivos de Zootecnia. Córdoba, v.59, n.225, p. 21-30, 2010.

SILVA, K. N. Caracterização molecular de Johnsongrass mosaic virus em plantas forrageiras dos gêneros brachiaria, panicum e pennisetum. 2015.

SILVA, R.R.; PRADO, I. N.; SILVA, F.F.; ALMEIDA, V.V S.; SANTANA JÚNIOR, H.A.; QUEIROZ, A. C.; BARROSO, D.S. Comportamento ingestivo diurno de novilhos Nelore recebendo níveis crescentes de suplementação em pastejo de capim-braquiária. Revista Brasileira de Zootecnia, v. 39, n. 9, p. 2073-2080, 2010. https://doi.org/10.1590/S1516-35982010000900028

SILVA, S.C.; NASCIMENTO JÚNIOR, D. Avanços na pesquisa com plantas forrageiras tropicais em pastagens: características morfofisiológicas e manejo do pastejo. Revista Brasileira de Zootecnia, v. 36, p. 122-138, 2007. https://doi.org/10.1590/S1516-35982007001000014

SILVA, S. Plantas forrageiras de A a Z / Sebastião Silva. 2.ed. - Viçosa, MG: Aprenda Fácil, 2014.

SOUZA, F.H.D. O papel das sementes no estabelecimento e na formação de pastagens. Campo Grande: EMBRAPA-CNPGC, 1993. 111 p.

SOUZA, J.R.; DE JESUS LACERDA, J.; MORAIS, O. M.; SILVA, J. P. Potencial germinativo de sementes incrustadas de espécies forrageiras tropicais. Ciência Rural, v. 47, n. 2, p. 1-6, 2017. https://doi.org/10.1590/0103-8478cr20151089

TAIZ, L.; ZEIGER, E. Fisiologia vegetal 3 ed. Porto Alegre: Artmed, v. 719, 2004. 
TEIXEIRA, F.A.; BONOMO, P.; PIRES, A.J.V.; SILVA, F.; MARQUES, J.; JÚNIOR, H. Padrões de deslocamento e permanência de bovinos em pastos de Brachiaria decumbens diferidos sob quatro estratégias de adubação. Revista Brasileira de Zootecnia, v. 40, n. 7, p. 1489-1496, 2011. https://doi.org/10.1590/S1516-35982011000700013

TSUMANUMA, G. M. Diversas espécies de braquiárias podem compor integração, 2009.

VILELA, H. Pastagem: seleção de plantas forrageiras, implantação e adubação. Aprender Fácil. Viçosa, 2005. 